[Hg4Te8(Te-2)(4)](8-) : A Heavy Metal Porphyrinoid Embedded in a Lamellar Structure

\title{
Donsbach, Carsten
}

2018-07-09

Donsbach , C , Reiter , K, Sundholm , D , Weigend, F \& Dehnen , S 2018 , '

[Hg4Te8(Te-2)(4)](8-) : A Heavy Metal Porphyrinoid Embedded in a Lamellar Structure ' ,

Angewandte Chemie (International Edition), vol. 57 , no. 28 , pp. 8770-8774 . https://doi.org/10.1002/anie.20180323

http://hdl.handle.net/10138/309478

https://doi.org/10.1002/anie.201803233

unspecified

acceptedVersion

Downloaded from Helda, University of Helsinki institutional repository.

This is an electronic reprint of the original article.

This reprint may differ from the original in pagination and typographic detail.

Please cite the original version. 
WILEY-VCH COMMUNICATION

\title{
$\left[\mathrm{Hg}_{4} \mathrm{Te}_{8}\left(\mathrm{Te}_{2}\right)_{4}\right]^{8-}:$ A Heavy Metal Porphyrinoid Embedded in a Lamellar Structure
}

\author{
Carsten Donsbach, ${ }^{[a]}$ Kevin Reiter,${ }^{[b]}$ Dage Sundholm, ${ }^{[c]}$ Florian Weigend, ${ }^{[b]}$ and Stefanie Dehnen ${ }^{\star[a]}$ \\ Dedicated to Professor Bernt Krebs on the occasion of his $80^{\text {th }}$ birthday.
}

\begin{abstract}
By use of ionic liquids $\left(\mathrm{C}_{n} \mathrm{C}_{1} \mid \mathrm{m}\right)\left[\mathrm{BF}_{4}\right]$ with long alkyl chains $(\mathrm{n}=10,12)$ at the ionothermal treatment of $\mathrm{Na}_{2}\left[\mathrm{HgTe}_{2}\right]$, lamellar crystal structures were obtained, with molecular macrocyclic anions $\left[\mathrm{Hg}_{8} \mathrm{Te}_{16}\right]^{8-}$ (1) representing the heaviest known topological relative of porphyrin. $\left[\mathrm{Hg}_{8} \mathrm{Te}_{16}\right]^{8-}$ naturally differs from porphyrin by the absence of an electronic $\pi$-system, which prevents a "global" aromaticity. Quantum chemical studies instead reveal small ring currents in the pyrrole-type five-membered rings that indicate weak local $(\sigma)$ aromaticity. Due to their layered nature, the compounds may be promising candidates for the generation of $2 \mathrm{D}$ chalcogenidometalate sheets.
\end{abstract}

Dimensional reduction of semiconductor materials is currently actively pursued to control and tune their electronic properties. ${ }^{[1]}$ In this context, post-synthetic methods beyond nano-particle formation, like stamping or exfoliation techniques, have picked up pace. ${ }^{[2]}$ Preconditions for the latter are twofold, (a) the presence of suitable semiconductor substructures and (b) relatively weak interactions in two dimensions within the parent compound. Both is fulfilled in layered elements like graphite or phosphorous, ${ }^{[3,4]}$ binary chalcogenides, ${ }^{[5]}$ or various inorganic-organic hybrid salts. ${ }^{[6]}$

Semiconductor nano-structures are also found in heavy-metal chalcogenidometalates that exhibit a large variety of elemental combinations and architectures. High-temperature reactions usually lead to neat structures, whereas solution-based routes afford more open frameworks with solvated or organic cations. The anionic substructures may comprise lower dimensionalities, down to molecular chalcogenidometalate units. ${ }^{[7]}$

An elegant way to transform semiconductor-based solids into hybrid compounds with weakly interacting organic cations is provided by ionothermal treatment of inorganic chalcogenidometalate salts. ${ }^{\left[{ }^{[8}\right.}$ Resulting substructures can be as uncommon as the $\left[\mathrm{Cu}_{5} \mathrm{Ga}_{30} \mathrm{~S}_{52}(\mathrm{SH})_{2}\left(\mathrm{C}_{4} \mathrm{C}_{1} \text { im }\right)_{2}\right]^{11-}$ cluster $\left(\mathrm{C}_{4} \mathrm{C}_{1}\right.$ im $=1$-butyl-3-methylimidazolyl), ${ }^{[9]}$ or the $0 \mathrm{D}-\left[\mathrm{Ge}_{24} \mathrm{Sn}_{32} \mathrm{Se}_{132}\right]^{24-}$

[a] C. Donsbach, Prof. Dr. S. Dehnen

Fachbereich Chemie and Wissenschaftliches Zentrum für Materialwissenschaften (WZMW), Philipps-Universität Marburg

Hans-Meerwein-Straße 4, 35043 Marburg (Germany)

E-mail: dehnen@chemie.uni-marburg.de

[b] K. Reiter, Priv.-Doz. Dr. F. Weigend

Institute of Nanotechnology, Karlsruhe Institute of Technology (KIT) Hermann-von-Helmholtz-Platz 1, 76344 Eggenstein-Leopoldshafen (Germany)

[c] Prof. Dr. D. Sundholm

Department of Chemistry, University of Helsinki

P. O. Box 55 (A.I. Virtanens plats 1), FIN-00014 University of Helsinki (Finland)

Supporting information for this article is given via a link at the end of the document. supersphere, ${ }^{[10]}$ the formation of which largely depends on the chosen temperatures, further auxiliaries, and the nature of the ionic liquid. ${ }^{[11]}$

One parameter to vary is the chain lengths of the alkyl substituents at the $\left(\mathrm{C}_{n} \mathrm{C}_{1} \mathrm{Im}\right)^{+}$cations in imidazolium-based ionic liquids. For $n=1-4$, the cations behave similar to spherical ones, hence their structure-directing effect does not generally differ from the variation of ionic radii of atomic cations. By contrast, longer alkyl chains cause the ionic liquid cations to assemble, for instance into herring-bone or lamellar structures. ${ }^{[12]}$

In the course of our studies regarding dimensional reduction of heavy-metal chalcogenidometalates, we are currently focusing on $\mathrm{Hg} / \mathrm{Te}$ substructures formally derived from the important II-VI semiconductor material $\mathrm{HgTe} .{ }^{[13]} \mathrm{By}$ ionothermal treatment of $\mathrm{Na}_{2}\left[\mathrm{HgTe}_{2}\right]$, comprising a one-dimensional [-Te- $\left.\mathrm{Hg}(\mathrm{Te})-\mathrm{Te}-\right]$ substructure, in the short-chain ionic liquid $\left(\mathrm{C}_{4} \mathrm{C}_{1} \mathrm{Im}\right)\left[\mathrm{BF}_{4}\right]\left(\mathrm{C}_{4} \mathrm{C}_{1} \mathrm{Im}\right.$ $=1$-butyl-3-methylimidazolium) at $60^{\circ} \mathrm{C}$, a salt comprising another one-dimensional strand was obtained upon partial Te oxidation (Scheme 1, left). ${ }^{[14]}$ However, the use of 1-(do)decyl-3methylimidazolium ionic liquids $\left(C_{n} C_{1} I m\right)\left[B F_{4}\right](n=10,12)$ affords salts of the unprecedented molecular anion $\left[\mathrm{Hg}_{8} \mathrm{Te}_{16}\right]^{8-}(\mathbf{1}$; Scheme 1, right) within a lamellar structure.

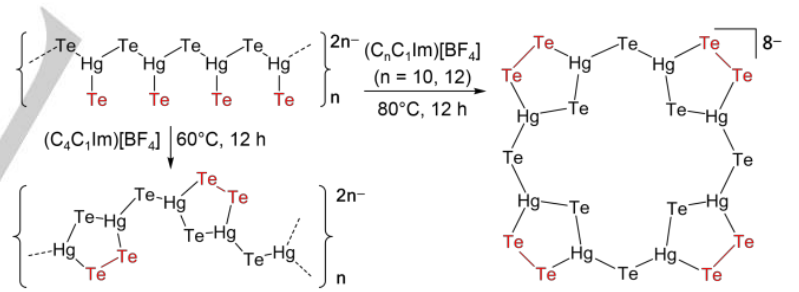

Scheme 1. Diagram of the strand-like anion in $\mathrm{Na}_{2}\left[\mathrm{HgTe}_{2}\right]$ (top left), and its treatment in ionic liquids $\left(\mathrm{C}_{n} \mathrm{C}_{1} \mathrm{Im}\right)\left[\mathrm{BF}_{4}\right]$, yielding another strand-like anion in the presence of short-chain imidazolium cations ( $n=4$, bottom left), ${ }^{[14]}$ or the molecular anion $\left[\mathrm{Hg}_{8} \mathrm{Te}_{16}\right]^{8-}(\mathbf{1})$ in ionic liquids with long-chain imidazolium cations ( $n=10,12$; this work).

$\left(\mathrm{C}_{10} \mathrm{C}_{1} \mathrm{Im}\right)_{8} \mathbf{1}$ crystallizes as thin, dark red plates in the monoclinic space group $P 2_{1} / C$, with four formula units per unit cell. The inorganic macrocycle in $\mathbf{1}$ is built by four $\left[\mathrm{Hg}_{2} \mathrm{Te}_{3}\right]$ five-membered rings comprising $\mathrm{Te}^{2-}$ and $\left(\mathrm{Te}_{2}\right)^{2-}$ ligands, which are bridged by four $\mathrm{Te}^{2-}$ ligands to form a cyclic tetramer. Hence, the anion 1 exhibits a close structural relation to organic porphyrins, which are composed of four methylene-bridged pyrrole rings, although the total valence electron count differs (120 in 1 versus 114 in porphyrin). 1 is thus related to the isoelectronic $\left[\mathrm{B}_{8} \mathrm{E}_{16}\right]$ structures of $\mathrm{BE}_{2}(\mathrm{E}=\mathrm{S}, \mathrm{Se}),{ }^{[15]}$ yet with the difference of being charged and with notable structural differences. Figure 1 illustrates the crystal structure of $\left(\mathrm{C}_{10} \mathrm{C}_{1} \mathrm{Im}\right)_{8} \mathbf{1}$. 


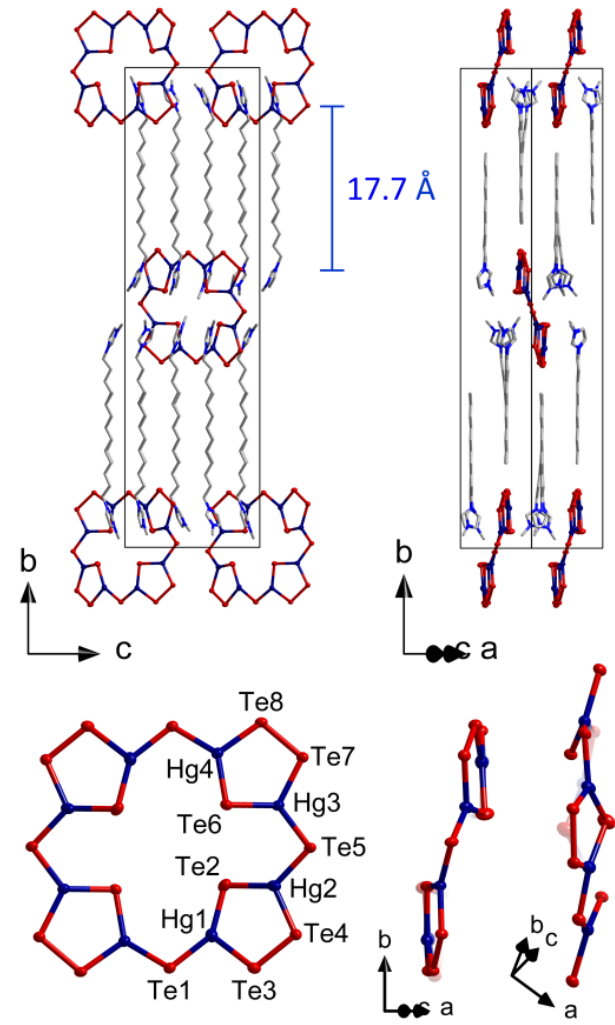

Figure 1. Top: Cut-out of the crystal structure of $\left(\mathrm{C}_{10} \mathrm{C}_{1} \mathrm{Im}\right)_{8} 1$ in different orientations. Bottom: molecular structure of the anion $\left[\mathrm{Hg}_{8} \mathrm{Te}_{16}\right]^{8-}(\mathbf{1})$ in different views $(\mathrm{Hg}$, Te: thermal ellipsoids at the $50 \%$ probability level. $\mathrm{C}, \mathrm{N}$ : wireframes. $\mathrm{H}$ atoms omitted for clarity). External diameters of the anion range from $12.3 \AA$ (Te1…Te1') to $16.2 \AA$ (Te7 $\cdots$ Te7').

Whereas Te-bridged $\left[\mathrm{Hg}_{2} \mathrm{Te}\left(\mathrm{Te}_{2}\right)\right]$ motifs have been aligned in one-dimensional chains, as found in the $\left(\mathrm{C}_{4} \mathrm{C}_{1} \mathrm{Im}\right)^{+}$salt mentioned above $^{14}$ and salts with $\left[\mathrm{N}\left(\mathrm{C}_{2} \mathrm{H}_{5}\right)_{4}\right]^{+}, \quad\left\{\left[\mathrm{Mn}(e n)_{3}\right]_{2} \mathrm{Cl}_{2}\right\}^{2+}$, or $\left[\mathrm{M}(\text { trien })\left(\mathrm{N}_{2} \mathrm{H}_{4}\right)\right]^{2+}(\mathrm{M}=\mathrm{Mn}, \mathrm{Zn})$ cations, ${ }^{[16]}$ a cyclic oligomer as found in 1 has not been known yet. The bond lengths in 1 [ Hg- $(\mu-$ Te) 2.692(2)-2.710(1), Hg- $\left(\mu: \eta^{1}: \eta^{1}-\mathrm{Te}_{2}\right)$ 2.762(1)-2.803(1), TeTe 2.728(2)-2.750(1)] are in good agreement with those of the related 1D- $\left\{\left[\mathrm{Hg}_{2} \mathrm{Te}_{4}\right]^{2-}\right\}$ anions $[\mathrm{Hg}-(\mu-\mathrm{Te}) 2.654(2)-2.729(5) \AA$; $\mathrm{Hg}-\left(\mu: \eta^{1}: \eta^{1}-\mathrm{Te}_{2}\right)$ 2.750(2)-2.807(2) $\AA$; Te-Te 2.736(2)-2.788(3) $\AA$ Å. All metal atoms possess a roughly trigonal planar coordination by three Te atoms (angle sums of $\geq 359.35(2)^{\circ}$ ), but the individual $\mathrm{Te}-\mathrm{Hg}-\mathrm{Te}$ angles cover a wide range $\left(102.73(4)^{\circ}-142.39(5)^{\circ}\right)$, with somewhat more obtuse $(\mu-\mathrm{Te})-\mathrm{Hg}-(\mu-\mathrm{Te})$ angles $\left[116.84(7)-137.12(6)^{\circ}\right.$ in the $1 \mathrm{D}$ strand] and slightly more acute $(\mu-\mathrm{Te})-\mathrm{Hg}-\left(\mu: \eta^{1}: \eta^{1}-\mathrm{Te}_{2}\right)$ angles [105.45(6)-127.73(7) ${ }^{\circ}$ in the 1D strand]. This indicates a significant coordinative flexibility around the $\mathrm{Hg}$ atoms that reacts on the respective arrangement of the counterions that vary in size, structure, charge, polarizability and hydrogen-bonding properties.

As a consequence of the coordinative flexibility of the $\mathrm{Hg}$ atoms, the macrocyclic anion $\mathbf{1}$ as a whole is not planar (Figure 1 , bottom right). In order to optimize the interaction and structural match with the imidazolium cations, opposite pairs of $\left[\mathrm{Hg}_{2} \mathrm{Te}_{3}\right]$ rings are inclined against each other by about $24.8(1)^{\circ}$. This way, the endocyclic Te atoms are relatively far apart from each other (Te...Te 7.0808(7)-7.4130(6) ^ across the center of 1). We note that the five-membered rings in the mentioned $1 \mathrm{D}-\left\{\left[\mathrm{Hg}_{2} \mathrm{Te}_{4}\right]^{2-}\right\}$ anionic chains are also not co-planar. Angles between mean planes (1.2(1)-35.0(6) ${ }^{\circ}$ ) span an even larger range, while in 1 this is naturally limited by its macrocyclic structure.

At the formation of $\mathbf{1}$, the anionic substructure of the starting material is re-organized, accompanied by (partial) oxidative coupling of the telluride ligands (dichalcogenide anions are relatively readily formed in ionic liquids, which are less "innocent" in this regard than originally anticipated) ${ }^{[8,14]}$. In the telluridomercurate anions of the starting material, $\left[\mathrm{HgTe}_{3}\right]$ triangles are linked by edge-sharing into one-dimensional [-Te$\mathrm{Hg}(\mathrm{Te})-\mathrm{Te}-]$ chains with all of the terminal Te atoms pointing towards the same side of the chain (Scheme 1). Thus, generation of $\mathrm{Te}-\mathrm{Te}$ bonds to form the $\left[\mathrm{Hg}_{2} \mathrm{Te}\left(\mathrm{Te}_{2}\right)\right]$ units may, in theory, occur without deconstruction of the chain. However, for the assembly of the oligomeric structure of $\mathbf{1}$, at least every tenth $\mathrm{Hg}-$ Te bond needs to be cut, and the five-membered rings need to rearrange by rotation about $\mathrm{Hg}-\mathrm{Te}$ bonds (Scheme $\mathrm{S} 1$ ). We ascribe the preference of $\left[\mathrm{Hg}_{8} \mathrm{Te}_{16}\right]^{8-}$ macrocycles over chain-like 1D$\left\{\left[\mathrm{Hg}_{2} \mathrm{Te}_{4}\right]^{2-}\right\}$ anions to the perfect fit of the molecular anions within the cationic template.

A closer look at the crystal structure of $\left(\mathrm{C}_{10} \mathrm{C}_{1} \mathrm{Im}\right)_{8} 1$ reveals segregation into ionic and nonpolar parts. The latter result from van-der-Waals interactions of the decyl chains that form a membrane-like interlocked double-layer with a width of $17.7 \AA$ (Figure 1, top). The positively charged imidazolium rings of the cations perfectly accommodate the anions as follows: two imidazolium rings are located in close proximity to one of the $\left[\mathrm{Hg}_{2} \mathrm{Te}\left(\mathrm{Te}_{2}\right)\right]$ rings each, four from the cationic layer above and four from the one below, and thus compensate for the anions' relatively high charge within the ionic layers. In this arrangement, the imidazolium rings are arranged orthogonal to the $\left[\mathrm{Hg}_{2} \mathrm{Te}\left(\mathrm{Te}_{2}\right)\right]$ units, thereby maximizing the anion $\cdots$ anion distance. The second compound obtained with longer alkyl chains, $\left(\mathrm{C}_{12} \mathrm{C}_{1} \mathrm{Im}\right)_{8} \mathbf{1}$, is isostructural to $\left(\mathrm{C}_{10} \mathrm{C}_{1} \mathrm{Im}\right)_{8} 1$. However, due to even thicker nonpolar layers within the solid state $(20.2 \AA$, Figure S4), it forms very thin and fragile crystals of relatively poor crystallographic quality (see the Supporting Information). The habitus of the plates points towards the potential of exfoliation, which is currently under exploration.

Beside segregation of long alkyl chains of such cations into polar/non-polar sections in the solid state, ${ }^{[17]}$ similar effects of nanoscale segregation into micro phases of homogeneous polarity was also observed in the liquid state of ionic liquids and confirmed by means of molecular dynamic simulations. ${ }^{[18,19]}$

Aside from the idea of dimensional reduction of semiconductors, the formation of heavy homologs of well-known molecules is a fascinating area of chemical research, informing about the correlation of intrinsic atomic properties, and the structural, chemical, and physical properties of molecules. Prominent examples include the series of ethane, ethene, or ethyne homologs formed by heavier main group atoms, with the typical impact on their molecular structures. ${ }^{[20]}$ Another recent example is $\mathrm{PbSe}$ acting as a CO-like bridging ligand in $\left\{\left[\left(\mathrm{Ph}_{3} \mathrm{P}\right)_{2} \mathrm{Rh}\right]\left[\left(\mathrm{Ph}_{3} \mathrm{P}\right)(\mathrm{CN}) \mathrm{Rh}\right]_{2} \mathrm{Se}_{2}(\mu-\mathrm{PbSe})\right\}^{3-}{ }^{3-{ }^{[21]}}$ Particularly worth noting are topological mimics of organic compounds by purely inorganic homologs - both with isoelectronic situations as well as 
under toleration of other electron counts. Molecules like the benzene analog borazine, $\mathrm{B}_{3} \mathrm{~N}_{3} \mathrm{H}_{6},{ }^{[22]}$ or the $\mathrm{P}_{5}{ }^{-}$anion as an isoelectronic equivalent of cyclopentidienide, $\mathrm{Cp}^{-},{ }^{[23]}$ have been well-known since decades, while more complex structures have remained rare. Besides the above-mentioned porphyrin-like structures of $\mathrm{BE}_{2}(\mathrm{E}=\mathrm{S}, \mathrm{Se})$, an inorganic double-helix mimicking DNA-like features was recently reported with the ternary, semiconducting phase SnIP. ${ }^{[24]}$

Quantum chemical studies were applied to explore electronic similarities and dissimilarities of this porphyrin-related molecule to porphyrin itself (TURBOMOLE, ${ }^{[25]}$ TPSSh functional,, ${ }^{[26]}$ def2TZVP bases, ${ }^{[27]}$ charge compensation with $\mathrm{COSMO}^{[28]}$ employing default parameters). Ring currents were obtained from GIMIC, ${ }^{[29]}$ based on the magnetic response calculated with a local version $^{[30,31]}$ of TURBOMOLE. Currents for the two systems are shown in Figure 2.

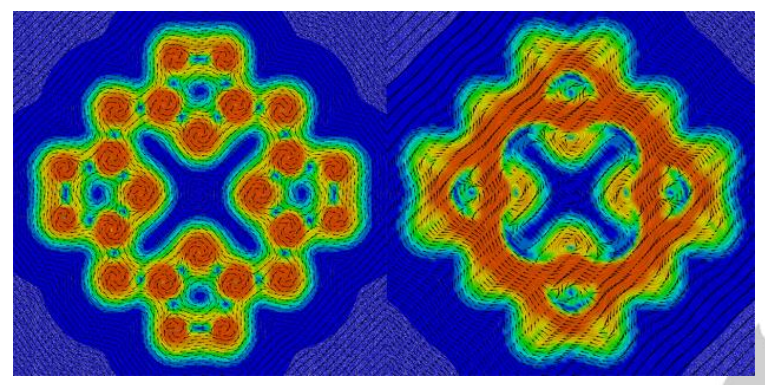

Figure 2. Ring currents, 1 bohr above the molecular plane of the inorganic anion 1 (left) and of organic porphyrin (right), drawn between 0 a.u. (blue) and 0.07 a.u. (red).

1 exhibits (weak) ring currents in the pyrrole-type five-membered rings. These currents consist of diatropic (clockwise, outside the ring) and paratropic (counterclockwise, inside) contributions of similar size but with a small surplus of the former leading to net currents of $+5.8 \mathrm{nA} / \mathrm{T}$. This is about half as much as for benzene, ${ }^{32}$ but - in contrast to the latter - they arise from sigma contributions only. The global net ring current (also consisting of diatropic and paratropic contributions) is essentially zero $(0.24 \mathrm{nA} / \mathrm{T})$. Organic porphyrines, in contrast, exhibit a global ring current of ca. 27 $\mathrm{nA} / \mathrm{T}$, which in the five-rings is split into two sub-currents, each amounting to ca. $13 \mathrm{nA} / \mathrm{T}$ [ $^{[32]}$

These differences correspond to very different electronic structures for the two systems (despite identical topology). Aromaticity and according currents in porphyrin is based on the delocalized $\pi$-electrons. Also in 1, there are delocalized canonical MOs, simply for symmetry reasons. The corresponding cluster orbitals (s-, p-, d-, f-, g-type) are the highest-energy MOs representing $\sigma$-bonding (Figure S7). However, in contrast to porphyrin, these MOs can be combined into two-center-twoelectron bonds and lone pairs by application of a localization procedure. ${ }^{[33]}$ This yields two lone pairs per Te atom, and single $\sigma$-type bonds between each pair of neighbored atoms (in total, 32 lone pairs and 28 bonds).

Optical absorption measurements were recorded on a singlecrystal of $\left(\mathrm{C}_{10} \mathrm{C}_{1} \mathrm{Im}\right)_{8} \mathbf{1}$ (Figure 3). The onset of absorption is found at $2.2 \cdots 2.8 \mathrm{eV}$, with a small shoulder of lower intensity at $2.1 \mathrm{eV}$.
This in excellent agreement with molecular TD-DFT calculations, with the lowest energy electronic transitions at $2.18 \mathrm{eV}$ (HOMO to LUMO), followed by two more intense transitions at $2.48 \mathrm{eV}$ (HOMO-4 to LUMO+3 and LUMO+4). During excitation, the electron density is essentially shifted from the $\mu$-Te lone pairs to antibonding Te-Te MOs.

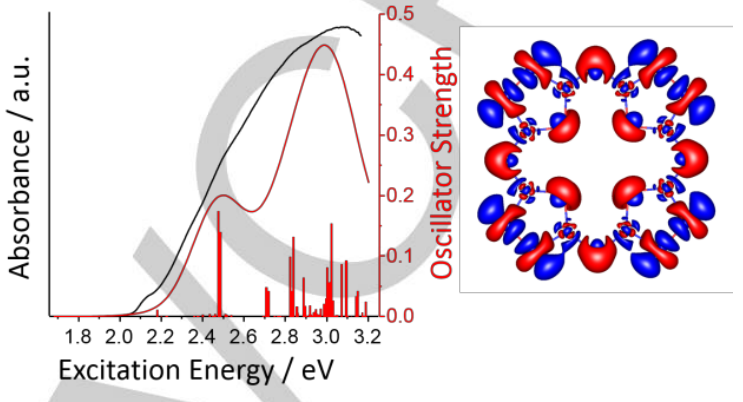

Figure 3. Comparison of the optical absorption spectrum measured on single crystals of $\left(\mathrm{C}_{10} \mathrm{C}_{1} \mathrm{Im}\right)_{8} 1$ (black line) with calculated singlet excitation energies and oscillator strengths (lowest 250 excitations), plotted as vertical red lines with superimposed Gaussians of fwhm $=0.3 \mathrm{eV}$ (red curve) to simulate the spectrum. The character of the entire band (up to $3.0 \mathrm{eV}$ ) is visualized using the nonrelaxed difference densities as described previously. ${ }^{[34]}$ The contributions of the occupied orbitals are plotted in red, those of the unoccupied orbitals in blue.

Due to the dimensional reduction, the optical gap is naturally blueshifted from solid $\mathrm{HgTe}(-0.26 \mathrm{eV})$ and 1D-[ $\left.\mathrm{Hg}_{2} \mathrm{Te}_{4}\right]^{2-}(1.63 \mathrm{eV})$ to $0 \mathrm{D}-\left[\mathrm{Hg}_{8} \mathrm{Te}_{16}\right]^{8-}(2.16 \mathrm{eV})$. It is still relatively narrow in the light of the given molecular size (24 atoms), as a consequence of the mixed-valence $\mathrm{Te}^{2-} /\left(\mathrm{Te}_{2}\right)^{2-}$ situation. As the absorption energy is likely to change upon complexation of transition metal atoms, we analyzed the possibility of using $\mathbf{1}$ as ligand. The lack of $\pi$ electrons in $\left[\mathrm{Hg}_{8} \mathrm{Te}_{16}\right]^{8-}$ comes along with a high structural flexibility (see above). As modelled by quantum chemistry, the macrocycle may accommodate metal ions of different sizes and coordination demands (e.g., $\mathrm{Ti}^{4+}, \mathrm{Cu}^{+}, \mathrm{Ce}^{4+}$ ) by adopting other shapes of the ring, which indeed show a different absorption behavior (Figure S8). It may be possible this way to form ternary complexes and clusters with tunable band gaps within lamellar arrangements. Yet, as the bonding energies are naturally lower than for corresponding porphyrin complexes the experimental isolation of according complexes remains a challenge.

In summary, we pursued a new approach for dimensional reduction of $\mathrm{Hg} / \mathrm{Te}$ motifs by ionothermal treatment of $\mathrm{Na}_{2}\left[\mathrm{HgTe}_{2}\right]$ in long-chain alkyl imidazolium-based ionic liquids. The obtained substructure represents purely inorganic macrocycles, $\left[\mathrm{Hg}_{8} \mathrm{Te}_{16}\right]^{8-}$ with porphyrine-related topology, that assemble in lamellar crystal structures. The anion notably derives from planarity in order to optimize its situation in between the imidazolium units of the lamellar counterion structure. As confirmed by quantum chemical studies, the lack of $\pi$-electrons prevents significant aromaticity but leads to high structural flexibility, which may allow the coordination of metal cations despite the macrocycle's size by adopting its structure to the requirement of the cation. This way, lamellar arrangements of allheavy-element complexes with tunable electronic properties may be accessible. 


\section{Experimental Section}

Details on experimental procedures (syntheses, single-crystal X-ray diffraction including CIF, spectroscopy, and quantum chemical studies) are available as Supporting Information free of charge on the Wiley- $\mathrm{VCH}$ Publications website.

\section{Acknowledgements}

This work was supported by the Deutsche Forschungsgemeinschaft within the frameworks of SPP 1708 and SFB 1176 (project Q5). It was also supported by The Academy of Finland through project 275845. CSC-IT Center for Science, Finland is acknowledged for computational resources. We thank Dr. N. Rinn, Dr. A. Rinn, J. Lange and Prof. Dr. S. Chatterjee for their help with the optical absorption spectra and M. Dimitrova for help with the GIMIC calculations.

Keywords: lonothermal synthesis • Chalcogenidometalates • Inorganic Macrocylces $•$ Dimensional Reduction $•$ Ring Currents

[1] a) Y. Pei, C. Chang, Z. Whang, M. Yin, M. Wu, G. Tan, H. Wu, Y. Chen, : Zhang, S. Ghong, T. Zhu, X. Zhao, L. Huang, J. He, M. G. Kanatzidis, L.D. Zhao, J. Am. Chem. Soc. 2016, 138, 16364-16371. b) X. Chen, X. Bu, Q. Lin, C. Mao, Y.-G. Zhai, Y. Wang, P. Feng, Chem. Eur. J. 2017, 23, 11913-11919. c) K. Zaho, C. Zhu, P. Qiu, A. B. Blichfeld, E. Eikeland, D. Ren, B. B. Iversen, F. Xu, X. Shi, L. Chen, Nano Energy 2017, 42, 4350.

[2] a) L. Dou, A. B. Wong, Y. Yu, M. Lai, N. Kornienko, S. W. Eaton, A. Fu, C. G. Bischak, J. Ma, T. Ding, N. S. Ginsberg, L.-W. Wang, A. P. Alivisatos, P. Yang, Science 2015, 349, 1518-1521. b) A. CastellanosGomez, M. Buscema, R. Molenaar, V. Singh, L. Janssen, H. S. J. van der Zant, G. A. Steele, $2 D$ Materials, 2014, 1, 011002. c) C. Tan, X. Cao, X.-J. Wu, Q. He, J. Yang, X. Zhang, J. Chen, W. Zhao, S. Han, G.-H. Nam, M. Sindoro, H. Zhang, Chem. Rev. 2017, 117, 6225-6331.

[3] K. S. Novoselov, A. K. Geim, S. V. Morozov, D. Jiang, Y. Zhang, S. V. Dobonos, I. V. Grigorieva, A. A. Firsov, Science 2004, 306, 666-669.

[4] R. Gusmão, Z. Sofer, M. Pumera, Angew. Chem. 2017, 129, 8164-8185 Angew. Chem. Int. Ed. 2017, 56, 8052-8072.

[5] a) G. Zhang, H. Liu, J. Qu., J. Li, Energy Environ. Sci. 2016, 9, 11901209. b) L. Li, Z. Chen, Y. Hu, X. Wang, T. Zhang, W. Chen, Q. Wang, J. Am. Chem. Soc. 2013, 135, 1213-1216. c) Y. Sun, H. Cheng, S. Gao, Q. Liu, Z. Sun, C. Xiao, C. Wu, S. Wei, Y. Yie, J. Am. Chem. Soc. 2012 134, 20294-20297.

[6] a) C. Zhou, H. Lin, Y. Tian, Z. Yuan, R. Clark, B. Chen, L. J. van de Burgt, J. C. Wang, Y. Zhou, K. Hanson, Q. J. Meisner, J. Neu, T. Besara, T. Siegrist, E. Lambers, P. Djurovich, B. Ma, Chem. Sci. 2018, 9, 586-593. b) A. Bayaguud, K. Chen, Y. Wei, Nano Research 2016, 9, 3858-3867.

[7] a) M. G. Kanatzidis, Inorg. Chem. 2017, 56, 3158-3173. b) M. J. Manosa, M. G. Kanatzidis, Chem. Sci. 2016, 7, 4804-4824. c) G. Thiele, T. Krüger, S. Dehnen, Angew. Chem. 2014, 126, 4787-4791; Angew. Chem. Int. Ed. 2014, 53, 4699-4703. d) S. Dehnen, M. Melullis, Coord. Chem. Rev. 2007, 251, 1259-1280. E) P. Feng, X. Bu, N. Zheng, Acc. Chem. Res. 2005, 38, 293-303.

[8] S. Santner, J. Heine, S. Dehnen, Angew. Chem. 2016, 128, 886-904. Angew. Chem. Int. Ed. 2016, 54, 876-893.

[9] W.-W. Xiong, J.-R. Li, B. Hu, B. Tan, R.-F. Li, X.-Y. Huang, Chem. Sci. 2012, 3, 1200-1204.
[10] Y. Lin, W. Massa, S. Dehnen, J. Am. Chem. Soc. 2012, 134, 4497-4500.

[11] a) R. E. Morris, Chem. Comm. 2009, 0, 2990-2998. b) S. Santner, J. Sprenger, M. Finze, S. Dehnen, Chem. Eur. J. 2018, 47, 1032-1035. c) S. Santner, S. Yogendra, J. J. Weigand, S. Dehnen, Chem. Eur. J. 2017, 23, 1999-2004.

[12] a) F. Neve, O. Francescangeli, A. Crispini, J. Charmant, Chem. Mater. 2001, 13, 2032-2041. b) A. Downard, M. J. Earle, C. Hardacre, S. E. J. McMath, M. Nieuwenhuyzen, S. Teat, Chem. Mater. 2001, 13, 20322041. c) A. Getsis, B. Balke, C. Felser, A.-V. Mudring, Cryst. Growth Des. 2009, 9, 4429-4437. d) M. Stricker, T. Linder, B. Oelckers, J. Sundermeyer, Green Chem. 2010, 12, 1589-1598.

[13] a) M. Cardona, R. Kremer, R. Lauck, G. Siegle, A. Muñoz, A. H. Romero, A. H. Phys. Rev. B 2009, 195204. b) A. Delin, T. Klüner, Phys. Rev. B 2002, 66, 035117. c) B. A. Bernevig, T. L. Hughes, S.-C. Zhang, Science 2006, 314, 1757-1761. d) M. König, S. Wiedmann, C. Brüne, A. Roth, H. Buhmann, L. W. Molenkamp, X.-L. Qi, S.-C. Zhang, Science 2007, 318, 766-770. e) A. Roth, C. Brüne, H. Buhmann, L. W. Molenkamp, J. Maciejko, X.-L. Qi, S.-C. Zhang, Science 2009, 325, 294-297.

[14] C. Donsbach, S. Dehnen, Z. Anorg. Allg. Chem. 2017, 643, 14-19.

[15] a) B. Krebs, H.-U. Hürter, Angew. Chem. 1980, 92, 479-480; Angew. Chem. Int. Ed. Engl. 1980, 19, 481-482. b) B. Krebs, H.-U. Hürter, Acta Crystallogr. A 1981, 37, C163b.

[16] a) J. Li, Z. Chen, J. L. Kelly, D. m. Proserpio, Mater. Res. Soc. Symp. Proc. 1997, 453, 29-34. b) S. S. Dhingra, C. J. Warren, R. C. Haushalter, A. B. Bocarsly, Chem. Mater. 1994, 6, 2382-2385. c) P. Sun, S. Liu, S. Li, L. Zhang, H. Sun, D. Jia, Inorg. Chem. 2017, 56, 6152-6162.

[17] T. Ito, Crystals 2016, 6, 24.

[18] A. Triolo, O. Russina, H.-J. Bleif, E. Di Cola, Phys. Chem. B 2007, 111, 4641-4644.

[19] R. Elfgen, O. Hollóczki, B. Kirchner, Acc. Chem. Res. 2017, 50, 29492957.

[20] R. C. Fischer, P. P. Power, Chem. Rev. 2010, 110, 3877-3923,

[21] G. Thiele, Y. Franzker, F. Weigend, S. Dehnen, Angew. Chem. 2015, 127, 11437-11442; Angew. Chem. Int. Ed. 2015, 54, 11283-11288.

[22] a) A. Stock, E. Pohland, Chem. Ber. 1926, 59, 2215-2223. b) R. Boese, A. H. Maulitz, P. Stellberg, Chem. Ber. 1994, 127, 18871889.

[23] O. J. Scherer, J. Schwalb, G. Wolmershäuser, W. Kaim, R. Gross, Angew. Chem. 1986, 98, 349-350; Angew. Chem. Int. Ed. Engl. 1986, 25, 363-364.

[24] D. Pfister, K. Schäfer, C. Ott, B. Gercke, R. Pöttgen, O. Janka, M. Baumgartner, A. Efimova, A. Hohmann, P. Schmidt, S. Venkatachalam, L. van. Wüllen, U. Schürmann, L. Kienle, V. Duppel, E. Parzinger, B. Miller, J. Becker, A. Holleitner, R. Weihrich, T. Nilges, Adv. Mat. 2016, 28, 9783-9791.

[25] TURBOMOLE Version 7.2, TURBOMOLE GmbH 2017. TURBOMOLE is a development of the University of Karlsruhe and the Forschungszentrum Karlsruhe 1989-2007, TURBOMOLE GmbH since 2007.

[26] V. Staroverov, G. Scuseria, J. Tao, J. Perdew, J. Chem. Phys. 2003, 119, 12129

[27] a) F. Weigend, R. Ahlrichs, Phys. Chem. Chem. Phys., 2005, 7, 32973305. b) F. Weigend, Phys. Chem. Chem. Phys. 2006, 8, 1057-1065. c) K. A. Peterson, D. Figgen, E. Goll, H. Stoll, M. Dolg, J. Chem. Phys. 2003, 119, 11113. d) D. Andrae, U. Häussermann, M. Dolg, H. Stoll, H. Preuß, Theor. Chim. Acta. 1990, 77, 123-141.

[28] A. Klamt, G. Schüürmann, J. Chem. Soc, Perkin Trans. 2 1993, 799

[29] J. Juselius, D. Sundholm, J. Gauss, J. Chem. Phys. 2004, 121, 3952.

[30] K. Reiter, M. Kühn, F. Weigend, J. Chem. Phys. 2017, 146, 054102.

[31] K. Reiter, F. Mack, F. Weigend, Chem. Theory Comput. 2018, 14, 191 197.

[32] H. Fliegl, D. Sundholm, J. Org. Chem. 2012, 77, 3408-3414.

[33] S. F. Boys, Rev. Mod. Phys. 1960, 32, 296-299.

[34] X.-X. Yang, I. Isaac, S. Lebedkin, M. Kühn, F. Weigend, D. Fenske, O. Fuhr, A. Eichhöfer, Chem. Commun. 2014, 50, 11043-11045. 


\section{Entry for the Table of Contents}

\section{COMMUNICATION}

Ionothermal treatment of $\mathrm{Na}_{2}\left[\mathrm{HgTe}_{2}\right]$ with $\left(C_{n} C_{1} I m\right)\left[B F_{4}\right](n=10,12)$ affords lamellar crystal structures embedding macrocyclic anions $\left[\mathrm{Hg}_{8} \mathrm{Te}_{16}\right]^{8-}(\mathbf{1})$, the heaviest known topological relative of porphyrin. In contrast to the latter, 1 does not exhibit a $\pi$-electron system, in accordance with its high structural flexibility, but possesses mall ring currents in the pyrrole-type fivemembered rings that indicate weak local $(\sigma)$ aromaticity.

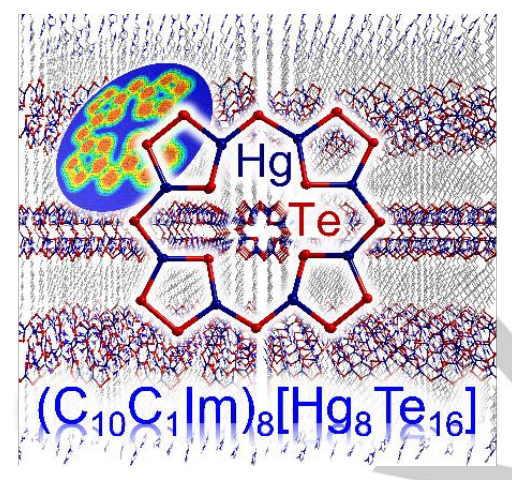

C. Donsbach, K. Reiter, D. Sundholm, F. Weigend, and S. Dehnen*

Page No. - Page No.

$\left[\mathrm{Hg}_{4} \mathrm{Te}_{8}\left(\mathrm{Te}_{2}\right)_{4}\right]^{8-}$ : A Heavy Metal Porphyrinoid Embedded in a Lamellar Structure 